\title{
Smart Hospital concept and its implementation capabilities based on the incentive extension
}

\author{
Oksana Ilyashenko ${ }^{1 *}$, Igor Ilin $^{1}$, and Dmitry Kurapeev ${ }^{2}$ \\ ${ }^{1}$ Peter the Great St. Petersburg Polytechnic University, Institute of Industrial Management, \\ Economics and Trade, Higher School of Business Management, 195251 Politekhnicheskaya st. 29, \\ Russian Federation \\ ${ }^{2}$ National Medical Research Center of V.A., 197341 Akkuratova st. 2, Russian Federation
}

\begin{abstract}
Currently, the health care as one of the priority development areas for the state requires special attention in the transition to the innovative management models based on the use of advanced medical concepts and digital technologies. Therefore, the transition to the SmartHospital model and the formation of an appropriate architectural solution become actual for health organizations which strategic task is the transition to the digital space and strengthening their positions in the medical services market. Prior to starting the development of the Smart Hospital architectural model as applied to the specific health organization, it is advisable to use a reference model that will take into account the basic business and IT requirements of the organization, limits and used technologies. The creation of the reference SmartHospital architectural solution is preceded by a preparatory stage that allows revealing the architecture and limit requirements. The article proposes the incentive extension on the basis of which the requirements and limits are formulated for the reference model of the SmartHospital architectural solution.
\end{abstract}

\section{Target setting}

The exponential potential growth and increase in capabilities of new technologies in medicine, the rapid IT development, development and implementation of the ideas of the 4th Industrial Revolution over the past few years have marked the prospect for formation of a completely different health care model.

Currently, the health care is considered as one of the priority spheres of development in many countries of the world. A key trend is search for promising opportunities in the social and economic fields. The social sphere mainly focuses on reducing mortality and a proportion of complex disease patients. The development of the health care system in the economic sphere proposes the creation of health organizations management system. Their strategic task is the transition to the digital space and strengthening their positions in the medical services market.

According to the Federal State Statistics Service, an average life expectancy increased by six months from January to May 2017 in Russia compared to 2016, and for the first time

\footnotetext{
* Corresponding author: ioy120878@gmail.com
} 
it exceeded 72 years and is 72.4 years. Mortality decreased by 3\% in 2017 compared with 2016 [1]. According to Deputy Prime Minister of the Russian Federation O. Yu. Golodets, the health and demographic development issues are the absolute priority of the Government [2].

One of the reasons for mortality reduction is the timely and quality provision of medical care based on the current medical concepts. Despite the decrease in the mortality rate, there is a number of trends in society that require increased attention to the solution of issues related to the treatment and prevention of diseases that are the main mortality factors (blood circulatory system diseases, cancerous diseases, infectious diseases, etc.). These trends include an increase in the average age of the population as a whole, an increase in life expectancy, an increase in the proportion of people over 65 , and a reduction in the number of young specialists graduating universities. As a result, there is a danger of growth of diseases, an increase in a proportion of complex disease patients in the population against the shortage of staff capable of providing highly skilled medical care. In this case, the health care delivery cost is steadily increasing at the moment. The problems solution all over the world is based on the use of the personalized medicine concept [3], achievements in biomedicine. These concepts and medicine technologies are implemented by means of the actual IT in the framework of the Health 4.0 concept [4]: IoT and IoS - Internet of Things and Internet of Services; cloud computing and Big Data; predictive analytics; block chain technologies; artificial intelligence and machine learning; developed mobile networks (5G).

The implementation of the above tasks requires the health organizations to transit to a completely different model of health care delivery that in turn requires changing in the management model of the health organization, namely, the transition to the Smart Hospital model. According to the European Union Agency for Network and Information Security (ENISA), the Smart Hospital is a health organization that provides health care and is based on optimized and automated processes built using the actual IT in accordance with the Health 4.0 concept to improve the existing procedure for patient care and to implement the advanced medical technologies [5]. The strategic objectives of the Smart Hospital are to provide extended patient care including remote medical services, to ensure efficient stream of patients and medical information, to increase diagnostic, surgical and organizational capabilities while maintaining the required level of patient information protection.

The Smart Hospital model introduction affects all levels of health organization management and requires re-engineering the health organization architecture as a whole or its separate components [6]. To create the target Smart Hospital model, it is advisable to use some reference model that will allow taking into account the main business and IT requirements of the organization, limits and the used technologies [7]. The formation of the reference Smart Hospital architectural solution is preceded by the preparatory stage associated with the incentive extension development that will provide the requirements for the architecture and limits. This study proposes the incentive extension on the basis of which it is possible to state the requirements and limits for the reference Smart Hospital architectural solution.

\section{Methods of research}

The development of the incentive extension of the reference architecture solution of the Smart Hospital model is based on the researchof M. Lankhorst [8]. The incentive concepts are used to simulate the motives or reasons underlying a design or a change of the enterprise architecture. They arrange and limit the design process, thereby affecting the result of the enterprise architecture design. These concepts are based on research for the development of the target requirements [9] and the architecture principles [10]. The result 
of incentive concept implementation is the incentive extension including concerned parties simulation, change factors, business objectives, principles, requirements and results. Let's consider each of the specified components of the incentive extension in more details with reference to the health organization implementing the Smart Hospital model.

\section{Research results}

Using the methodology for building the incentive concept proposed by M. Lankhorst and its graphic representation as the incentive extension, we will form the latter for the reference model of the Smart Hospital architectural solution.

First of all, we will define the stakeholders of the health organization implementing the SmartHospital model. In our opinion, for the health organization, the stakeholders interested in the organization development are:

- top management of the health organization represented by the head;

- The Ministry of Healthcare of the Russian Federation that is an economic and legal mechanism for control for the development of the entire health care system and individual health clinics. The Ministry of Healthcare of the Russian Federation controls for an amount of financing health clinics, the development strategy of the entire health care system, taking into account the social and economic situation in the country, the world healthcare development trends, etc ;

- the Suppliers of medical equipment and drugs interested in implementation of value- and actual IT based personalized medicine concepts by health clinics.

- insurance companies interested in developing partnerships with health clinics to implement various health insurance routes.

The main drivers of the health organization that encourage the organization to implement the Smart Hospital model and perform the corresponding architecture reengineering are:

- $\quad$ using a new medical and information technologies [11];

- changes in the legislation, namely, the law on telemedicine effective from January 1, 2018 [12], the strategy for development of the healthcare of the Russian Federation for the long-term period 2015-2030 [13]. Implementation of telemedicine technologies capability qualitatively changes the system of organization at interaction with patients and, as a result, the system of business processes and IT support of health clinics;

- the increasing cost of medical services delivery takes up the matter with health clinics to revise the patient stream management system, personnel capacity, etc.;

- population aging and a change in the diseases spectrum, high mortality and incidents of certain types of diseases, such as cardiovascular diseases (CVD), cancerous diseases. This leads to the need to change the medical services system in terms of development of the prevention and early disease detection system.

The analysis of the situation in health clinics from the point of view of the listed drivers allowed stating the following assessments: presently, in the most clinics there is no corresponding management model and IT infrastructure that would allow meeting the above social challenges to modern medicine. Another important assessment of the health clinics activity as a result of the stated factors being the reason of changes in architecture is the ineffectiveness of the resource allocation system, especially with regard to patient stream management and the use of human resources. This allowed to state the goals facing health clinics. Taking into account the existing social problems, world trends in medical and information technologies, the identified management problems in health clinics, the goals of the clinics architecture development are increasing the efficiency of health 
organizations, on the one hand, with a steady increase in the medical care quality, on the other hand. The achievement result of the stated goals will be the Smart Hospital model implementation based on the Health 4.0 concept and the implementation of the "4P" medicine principles [14]. The use of the Health 4.0 technologies-cloud computing, IoT, Big data, predictive analytics, machine learning and artificial intelligence, block chain technologies and mobile technologies - combined with the "4P" concept [15] - value-based, personalized, predictive and participatory medicine - are the key requirements for the reference architectural solution functionality and allow implementing a number of intermediate results, which integrated combination will provide a transition to the Smart Hospital model: the dominant position of the health organization in the market of monitoring and treatment of remote patients; implementation of services providing the Health 4.0 concept implementation; automation of business and operational processes; transition from disease-oriented effectiveness criteria to patient-oriented ones [16].

It should be noted that the achievement of these results is possible only when observing a number of requirements both for a Smart Hospital architectural solution functional and personnel training mentioned above. To solve the tasks for automation of business and operational processes, implementation of remote monitoring, transition to patient-oriented effectiveness criteria, it is required to extend the specialists competence in obtaining interdisciplinary knowledge by health workers. The necessary condition of the successful subdivisions management for employees performing administrative functions is the formation of management competencies, which vector is directed towards the digital health clinic transformation.

When implementing this clinic architecture functionality, it is necessary to take into account a number of limits. First, the activities digitizing proposes the use of cloud computing. In this case, it is necessary to take into account the limits associated with the use of patient personal data. The use of block chain technologies is required to arrange the required level of information security and access to data in accordance with the implemented security policy in the health clinic. Secondly, considering the import substitution concept, there are recommendations for the software use including domestic information systems [17]. 


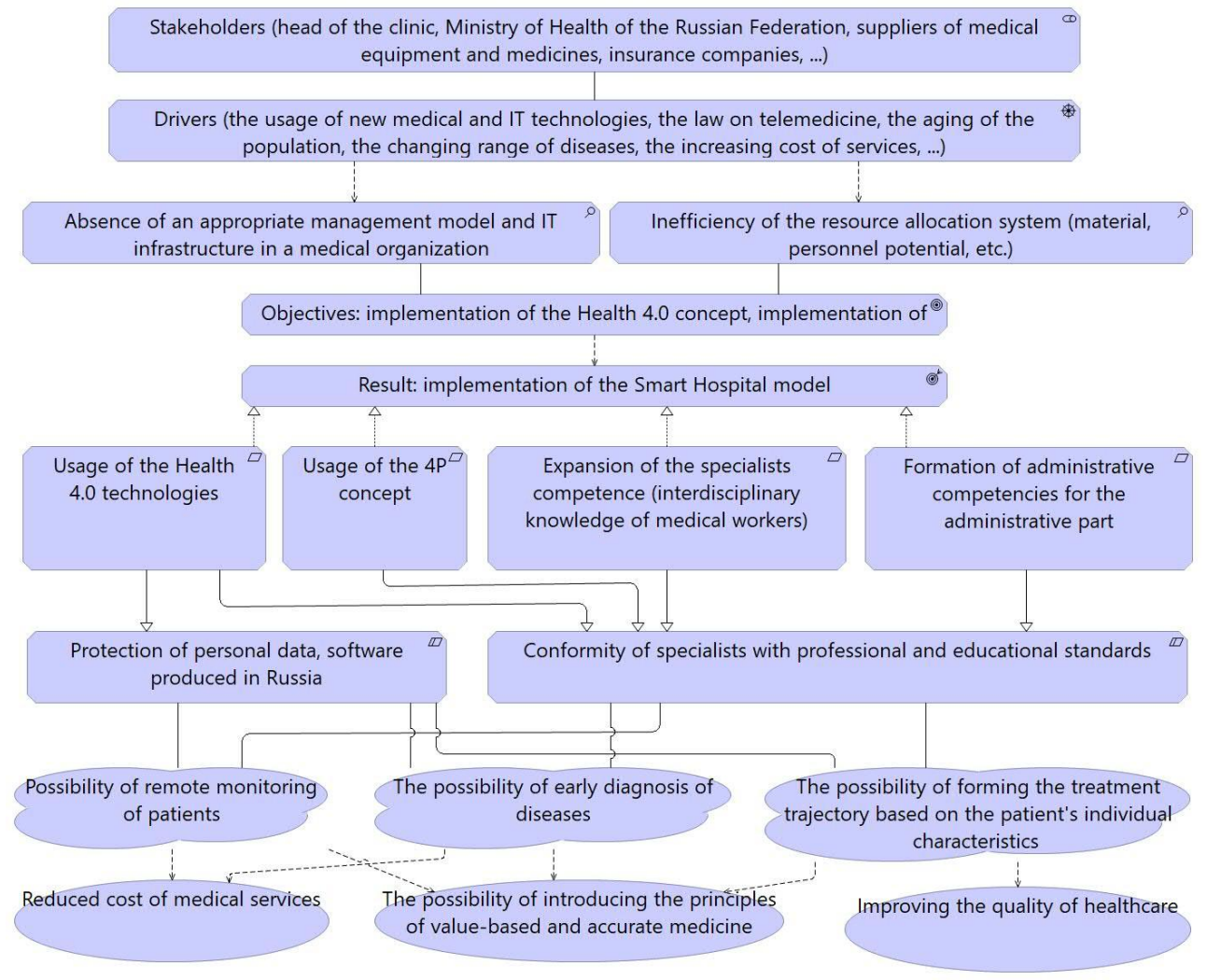

Fig. 1.The enlarged scheme of the incentive extension of the reference architectural solution of the health organization implementing the Smart Hospital concept.

To fulfill the requirements regarding the development of the competence of the medical organization personnel, it is necessary to pay attention to the personnel training in accordance with the changing professional and educational standards of medical education [18]. Employees holding managerial positions (at the department chief level and higher) must have managerial competencies. To this end, it is required to form a specialist model who manages the structural subdivisions of the health organization or the organization as a whole that has not only the professional doctor competencies but also has a set of management competencies that will promptly respond to changes in the requirements of the external and internal environment and take appropriate decisions in terms of managing development of the organization as a whole or its separate components.

The incentive extension result is formation of the simulated architectural solution value and its value for the health organization as a whole or for its separate components. The main values for the health organization implementing the Smart Hospital model are remote patients monitoring that is especially important for such a territorially extended country as the Russian Federation; early diseases detection that will allow implementing actual medicine strategies: early diseases detection in combination with risk factors control; the possibility for arranging a treatment ways based on the individual patient characteristics. This will allow a health clinic to implement the value-based and personalized medicine principles while reducing the medical services cost. This incentive extension value is an actual problem of the modern health care system, as medical services cost is now growing exponentially. As a result of the description of the main components of the incentive extension in accordance with the M. Lankhorst's methodology, the incentive extension was 
formed for the reference architectural solution of the health organization implementing the Smart Hospital concept (Fig. 1).

\section{Conclusions}

As a result of the study, the existing socioeconomic problems are described, which as a whole the health system and health organizations being the main health care providers deal with. The paper considers the medical concepts that require the support of actual digital technologies, justifies the feasibility of creating the reference model of the Smart Hospital architectural solution. The model building proposes a preliminary description of the relevant requirements and limits. A methodology for creating the incentive extension proposed by M. Lankhorst was used as a method for creating the upper-level requirements and limits for the reference model of the Smart Hospital architectural solution. In the future, it is planned to propose the reference Smart Hospital architectural solution taking into account the identified requirements and limits.

\section{References}

1. Federal State Statistics Service [online] Available at: www.gks.ru/free_doc/2017/demo/t3_3.xls (2018).

2. Delovoy Peterburg [online] Available at: https://www.dp.ru/a/2017/08/14/Srednjaja_prodolzhitelnost (2018).

3. V. A. Stepanov, Personalized medicine: challenges and solutions [online] Available at: http://www.sbras.ru/files/files/prezidium20171221/ 5 stepanov-persmed-pressorannsk-dec2017.pdf (2017).

4. By 2020 the Smart Hospital will be a reality [online] Available at: https://www.futurehealthindex.com/2017/06/13/by-2020-the-smart-hospital-will-be-areality/ (2018).

5. European Union Agency for Network and Information Security [online] Available at: file:///C:/Users/User/Downloads/Smart\%20Hospitals\%20(1).pdf (2018).

6. I. V. Ilin, O. Yu. Iliashenko, A. I. Levina, Reengineering of high-tech and specialized Medical care delivery process for telemedicine system implementation. Proceedings of the 29th International Business Information Management Association Conference Sustainable Economic Growth, Education Excellence, and Innovation Management through Vision 2020,1822-1831.

7. I. V. Ilin, K. V. Frolov, A. A. Lepekhin, From Business Processes Model of the Company to Software Development: MDA Business Extension. Proceedings of the 29th International Business Information Management Association ConferenceSustainable Economic Growth, Education Excellence, and Innovation Management through Vision 2020, 1157-1164 (2017)

8. M. Lankhorst et al. Enterprise Architecture at Work. Modeling, Communication and Analysis (2017)

9. A. V. Lamsweerde, Goal-oriented requirements engineering: A roundtrip from research to practice. $12^{\text {th }}$ IEEE Joint International Requirements Engineering Conference. RE'04. Kyoto, Japan (2004)

10. D. Greefhorst, Proper, E. Architecture Principles. The Cornerstones of Enterprise Architecture. Springer (2011) 
11. JC Hsieh, AH Li, CC Yang. Mobile, cloud, and big data computing: contributions, challenges, and new directions in telecardiology. Int $J$ Environ Res Public

Health 10(11), 6131-53 (2013)

12. Federal Law No. 242-FZ dd. 29.07.2017 "On introduction of changes to some legislative acts of the Russian Federation regarding application of information technologies in health care" [online] Available at:

http://publication.pravo.gov.ru/Document/View/0001201707300032 (2017)

13. The Russian Federation Health Development Strategy for the Long-term Period of 2015-2030 [online] Available at:

https://old2015.rosminzdrav.ru/ministry/61/22/stranitsa-979/strategiya-razvitiyazdravoohraneniya-rossiyskoy-federatsii-na-dolgosrochnyy-period (2017)

14. L. Hood. Systems Biology and P4 Medicine: Past, Present, and Future. Rambam Maimonides Med J. 4(2), (2013) [online] Available at: https://www.ncbi.nlm.nih.gov/pmc/articles/PMC3678833/ (2017)

15. Jong-Myon Bae Value-based medicine: concepts and application. Epidemiol Health. 37 (2015)

16. Cardiovascular risk factors in hypothyroidism in the populations of the Russian Federation and the USA.

V. G. Vilkov, S. A. Shalnova, A. O. Konradi, Yu. V.Zhernakova, S. A. Boytsov, Profilakticheskaya Meditsina (2016)

17. Round table "Import substitution in IT equipment: requirements of Customers and ways of their implementation" [online] Available at:

http://sipower.ru/novosti/item/256-kruglyj-stol-importozameshchenie-v-itoborudovanii.html (2017)

18. E. A. Ryngach, T. V. Treshkur, A. A. Tatarinova, E. V. Shlyakhto, Algorithm for the management of patients with stable coronary artery disease and high-grade ventricular arrhythmias Terapevticheskii Arkhiv (2017) 